\title{
PENGARUH RELATIONSHIP MARKETING DAN KUALITAS LAYANAN TERHADAP LOYALITAS NASABAH TABUNGAN SIKOCI PADA BANK NAGARI CABANG SIMPANG EMPAT
}

\author{
Lola Satri, Alfian \\ STIE "KBP" PADANG \\ lolasatri084@gmail.com
}

\begin{abstract}
This research has a purpose to know whether relationship marketing and service quality have positive influence to loyalty of customer of saving sikoci at Bank of Nagari branch of Simpang Empat either partially or simultaneously and know which variable is more dominant. The data collection techniques used in this study is a questionnaire. The sample used is 100 customer, with sampling technique using accidental sampling technique. Data analysis technique in this research use multiple linear regression analysis. The results obtained in this study are as follows: (1) Trust has positive effect (944) <(1,984) and not significant $(0,348)>(0,05)$ to loyalty. (2)) Commitment has positive $(8,218)>(1,984)$ and significant $(0,000)<(0,05)$ effect on loyalty. (3) Tangibles has negative $(-2,430)>(1,984)$ and significant $(0,017)<(0,05)$ effect on loyalty. (4) Reliability negatively $(-1.570)<(1,984)$ and insignificant $0,120>0.05$ to loyalty. (5) Responsiveness has positive effect $(5,922)>t$ table $(1,984)$ and significant $(0,000)$ $<(0,05)$ to loyalty. (6) Warranty has positive effect $(1,199)<(1,984)$ and insignificant 0 , 234> 0,05 to loyalty. (7) Empathy has positive effect $(186)<(1,984)$ and insignificant 0, $853>0,05$ to loyalty. From the value of Adjusted $R$ Squere simultaneously produced 566. It means that $56.6 \%$ of loyalty variables are influenced by independent variables and the remaining $43.4 \%$ is influenced by othervariables.
\end{abstract}

Keywords: Trust, Commitment, Tangibles, Reliability, Responsiveness, Assurance, Empathy, Loyalty

\section{PENDAHULUAN}

Perkembangan dan pertumbuhan perekonomian yang sangat pesat mendorong persaingan yang ketat antar perusahaan jasa. perusahaan jasa yang mengalami persaingan yang cukup ketat pada saat ini adalah perbankan. Perbankan merupakan perusahan jasa yang berdasarkan kepada azas kepercayaan. Agar bisa mempertahankan eksistensi dan memenangkan persaingan, perusahaan dituntut agar lebih mengembangkan strategi pemasaran secara tepat, yaitu dengan memuaskan kebutuhan dan keinginan nasabah. Berbagai strategi pemasaran diterapkan agar dapat meraih loyalitas nasabah. Strategi pemasaran yang dilakukan perusahaan, diantaranya dengan menciptakan hubungan baik jangka panjang dengan nasabah serta memberikan pelayanan yang berkualitas (Wulandari, 2007:270) dalam (Ratnawati, 2011)

Loyalitas merupakan aspek penting bagi perusahaan perbankan untuk mempertahankan eksistensinya agar bisa memenangkan persaingan dengan menjaga nasabah yang ada dan menarik nasabah lain. Beberapa upaya perusahaan dalam mencapai loyalitas adalah dengan menjalin relasi atau hubungan (Relationship Marketing) dengan nasabah. Relasi atau hubungan (Relationship Marketing) banyak dijumpai sebagai salah satu strategi penentu loyalitas. Selain 
dengan strategi Relationship Marketing, pelayanan yang berkualitas juga dilakukan agar terciptanya loyalitas nasabah. Kualitas layanan yang baik diharapkan bisa menentukan sikap nasabah dalam menilai, memutuskan sekaligus memberikan kesan terhadap layanan yang diberikan, sebab konsumen yang merasa puas lebih cenderung loyal terhadap perusahaan itu.

Bank Nagari adalah salah satu perusahaan yang bergerak pada bidang jasa perbankan yang dimiliki oleh pemerintah Sumatra Barat yang menjalankan kegiatan operasional dalam melayani kebutuhan masyarakat. Saat ini Bank Nagari sudah memiliki kemajuan pesat dibuktikan telah berdirinya banyak cabang yang berdiri di berbagai kota di Indonesia termasuk Bank Nagari cabang Simpang Empat.

Bank Nagari cabang Simpang Empat sebagai salah satu kantor cabang dari Bank Nagari Sumatera Barat yang berada di di Pasaman Barat. Untuk hal pelayanan nasabah mempunyai pelayanan yang sama dengan kantor cabang lainnya. Antara satu kantor cabang dengan kantor cabang lain mempunyai sistem kerja yang sama, tetapi dari pelaksanaan sehari-hari masing-masing cabang mempunyai perbedaan yang bersifat personal dan budaya daerah masing-masing.

Tabungan sikoci telah dikenalkan pada masyarakat mulai dari tahun 2001 dan mempunyai tujuan dalam rangka menghimpun dana dari masyarakat. Tabungan sikoci merupakan salah satu produk unggulan yang dimiliki Bank Nagari yang di harapkan mampu mengumpulkan dana dari masyarakat lebih banyak lagi pada waktu yang mendatang.

Berikut ini disajikan jumlah nasabah Tabungan Sikoci pada Bank Nagari cabang Simpang Empat dari tahun 2012-2016 seperti yang dikemukakan pada tabel 1.1 berikut ini :

Tabel 1

Data Jumlah Nasabah Tabungan Sikoci Bank Nagari Cabang Simpang Empat Tahun 2012-2016

\begin{tabular}{|l|l|}
\hline Tahun & Jumlah Nasabah \\
\hline 2012 & 16.088 \\
\hline 2013 & 16.841 \\
\hline 2014 & 18.748 \\
\hline 2015 & 19.034 \\
\hline 2016 & 21.838 \\
\hline
\end{tabular}

Dari data diatas dapat di simpulkan data jumlah nasabah tabungan sikoci pada tahun 2012 sebesar 16.088, pada tahun 2013 jumlah nasabah tabungan sikoci sebesar 16.841 jumlah nasabah tabungan sikoci mengalami peningkatan, pada tahun 2014 jumlah nasabah tabungan sikoci sebesar 18.748 mengalami kenaikan, pada tahun 2015 jumlah nasabah tabungan sikoci sebesar 19.034 mengalami peningkatan, pada tahun 2016 jumlah nasabah tabungan sikoci sebesar 21.838 jumlah nasabah tahun ini juga meningkat. Dalam lima tahun terakhir ini Bank Nagari cabang Simpang Empat dalam menghimpun dana dari masyarakat dalam bentuk Tabungan Sikoci selalu mengalami peningkatan pada jumlah nasabahnya dan sudah tidak ada lagi penurunan. Kita mengharapkan jumlah nasabah tabungan sikoci selalu mengalami peningkatan seperti ini setiap tahunnya. Dengan meningkatnya jumlah nasabah tabungan sikoci ini tentunya diharapkan peningkatan jumlah nasabah diiringi dengan peningkatan kualitas 
pelayanan. Peningkatan pelayanan perlu dilakukan secara terus menerus, apalagi Bank sebagai lembaga kepercayaan masyarakat, sehingga hal tersebut akan menjadi sangat penting.

Bank Nagari cabang Simpang Empat juga dituntut untuk memberikan pelayanan yang memuaskan dan membina hubungan baik dengan nasabah melalui Relationship Marketing mengingat tingginya persaingan. Konsep ini mengharapkan adanya inovasi dan peningkatan kualitas layanan agar dapat menciptakan loyalitas nasabah terhadap Bank Nagari cabang Simpang Empat sehingga tercipta hubungan jangka panjang yang baik antara perusahaan dan pelanggan.

\section{Pengertian Loyalitas}

Loyalitas pelanggan adalah komitmen untuk bertahan secara mendalam untuk melakukan pembelian ulang atau berlangganan kembali produk atau jasa terpilih secara konsisten di masa yang akan datang, meskipun pengaruh situasi dan usahausaha pemasaran mempunyai potensi untuk menyebabkan perubahan perilaku (Oliver dikutip dalam Gaffar, 2007: 70).Faktor-faktor untuk mengembangkan loyalitas

Menurut Griffin (2005) dalam (Ratnawati, 2011) terdapat dua faktor yang penting untuk mengembangkan loyalitas adalah : Keterikatan (Attachment) yang tinggi terhadap produk atau jasa tertentu dibanding produk atau jasa pesaing potensial dan Pembelian berulang yang tinggi terhadap produk atau jasa tertentu dibanding dengan produk lain dari pesaing.

\section{Pengertian Relationship Marketing}

Relationship marketing adalah proses menciptakan, mempertahankan dan meningkatkan hubungan yang kuat, bernilai tinggi dengan pelanggan atau organisasi harus memfokuskan pada mengelola pelanggan disamping produk relationship marketing sendiri mendorong para marketer untuk selalu berfikir dalam waktu yang panjang (Kotler, 2007 : 194).

Saputra (2008:74) dalam (Sungkono, 2014) menyatakan bahwa relationship marketing dibentuk oleh 4 faktor meliputi :

1. Kepercayaan

Adalah keyakinan yang dimiliki dalam hubungan dengan rekan kerja terkait dengan sikap jujur dan saling membantu satu sama lain.

2. Komitmen

Adalah suatu keyakinan antara pihak terkait yang menginginkan adanya hubungan yang terus menerus, dan dinilai penting dalam rangka menjaga hubungan tersebut.

3. Komunikasi

Komunikasi dalam relationship marketing berhubungan dengan nilai yang diperoleh pelanggan, memberikan informasi yang tepat dan dapat dipercaya serta informasi mengenai adanya perubahan jasa yang ditawarkan, dan komunikasi yang proaktif ketika terjadi masalah perusahaan dan pelanggan.

4. Penanganan konflik

Adalah penanganan konflik merupakan tindakan khusus pada saat melakukan interaksi dengan pelanggan.

\section{Pengertian Kualiatas Pelayanan}

Menurut kotler dan amstrong (2004:337) dalam (Widyastuti, 2014) pelayanan adalah berbagai kegiatan atau manfaat yang dapat ditawarkan oleh 
suatu pihak kepada pihak lain yang pada dasarnya tidak berwujud, dan tidak menghasilkan perpindahan kepemilikan. Pelayanan adalah sarana untuk mengidentifikasi dan memenuhi superior need. Dengan kata lain layanan konsumen menjadi pusat keuntungan konsumen.

Pelayanan yang berkualitas perlu diberikan oleh perusahaan selain untuk menarik minat konsumen untuk menggunakan barang/jasa, tetapi juga memberikan kepuasan kepada konsumen dan pada akhirnya konsumen akan datang untuk melakukan pembelian berulang.

\section{indikator kualitas pelayanan}

Menurut Tjiptono (2010) dalam (Ratnawati, 2011) indikator kualitas pelayanan meliputi SERQUAL (Service quality), yaitu sebagai berikut :

1. Bukti fisik (Tangibles)

Meliputi fasilitas fisik, perlengkapan, karyawan dan sarana komunikasi

2. Keandalan (Reliability)

Yakni kemampuan memberikan layanan yan dijanjikan dengan segera, akurat, dan memuaskan. Hal ini berarti perusahaan memberikan pelayanan yang tepat.

3. Ketanggapan (responsiveness)

Yaitu keinginan dan kesediaan para karyawan untuk membantu para pelanggan dan memberikan pelayanan dengan sebaik mungkin.

4. Jaminan (Assurance)

Yakni mencakup pengetahuan, kompetensi, kesopanan, dan sifat dapat dipercaya yang dimiliki para karyawan, bebas dari resiko, bahaya fisi atau keragu-raguan

5. Empati (Empaty)

Meliputi kemudahan dalam menjalin hubungan, komunikasi yang efektif, perhatian personal dan pemahaman atas kebutuhan individual para pelanggan

\section{Hipotesis Penelitian}

$\mathrm{H}_{1}$ : Diduga kepercayaan berpengaruh signifikan positif terhadap loyalitas nasabah tabungan sikoci

$\mathrm{H}_{2}$ : Diduga komitmen berpengaruh signifikan positif terhadap loyalitas nasabah tabungan sikoci

$\mathrm{H}_{3}$ : Diduga bukti fisik (tangibles) berpengaruh signifikan positif terhadap loyalitas nasabah tabungan sikoci

$\mathrm{H}_{4}$ : Diduga keandalan (reliability) berpengaruh signifikan positif terhadap loyalitas nasabah tabungan sikoci

$\mathrm{H}_{5}$ : Diduga ketanggapan (responsiveness) berpengaruh signifikan positif terhadap loyalitas nasabah tabungan sikoci

$\mathrm{H}_{6}$ : Diduga jaminan (assurance) berpengaruh signifikan positif terhadap loyalitas nasabah tabungan sikoci

$\mathrm{H}_{7}$ : Diduga empati (empaty) berpengaruh signifikan positif terhadap loyalitas nasabah tabungan sikoci

\section{Jenis penelitian}

Jenis penelitian ini adalah penelitian yang bersifat deskriptif dengan menggunakan pendekatan kuantitatif. Pendekatan kuantitatif yaitu salah satu metode penelitian dimana data penelitian berupa angka-angka dan analisis menggunakan statistik (Sugiyono, 2015). 
Penelitian kuantitatif untuk menjawab rumusan masalah digunakan konsep atau teori sehingga dapat dirumuskan hipotesis. Tujuannya yaitu untuk menguji hipotesis yang ditetapkan.

Populasi merupakan wilayah generalisasi yang terdiri atas subjek atau objek yang mempunyai kuantitas dan karakteristik tertentu yang ditetapkan oleh peneliti untuk dipelajari dan kemudian ditarik kesimpulannya (Sugiyono, 2015). Yang menjadi populasi dalam penelitian ini adalah seluruh nasabah tabungan sikoci pada Bank Nagari cabang Simpang Empat, dengan jumlah populasi sebanyak 21.838 orang nasabah tabungan sikoci pada akhir tahun 2016. . jadi besar sampel penelitian adalah 100 orang yang dihitung menggunakan rumus slovin.

HASIL DAN PEMBAHASAN.

Analisis Regresi Linear Berganda

\begin{tabular}{|c|c|c|c|c|c|}
\hline \multicolumn{6}{|l|}{ Coefficients $^{\mathrm{a}}$} \\
\hline \multirow[b]{2}{*}{ Model } & \multicolumn{2}{|c|}{\begin{tabular}{|l|} 
Unstandardized \\
Coefficients
\end{tabular}} & \multirow{2}{*}{\begin{tabular}{|l} 
Standardized \\
Coefficients
\end{tabular}} & \multirow[b]{2}{*}{$\mathrm{T}$} & \multirow[b]{2}{*}{ Sig. } \\
\hline & $B$ & Std. Error & & & \\
\hline 1 (Constant) & .948 & 2.405 & & .394 & .694 \\
\hline $\mathrm{X} 1$ & .085 & .091 & .090 & .944 & .348 \\
\hline $\mathrm{X} 2$ & .595 & .072 & .565 & 8.218 & .000 \\
\hline $\mathrm{X} 3$ & -.208 & .086 & -.224 & -2.430 & .017 \\
\hline $\mathrm{X} 4$ & -.106 & .068 & -.110 & -1.570 & .120 \\
\hline $\mathrm{X} 5$ & .453 & .077 & .441 & 5.922 & .000 \\
\hline X6 & .087 & .073 & .092 & 1.199 & .234 \\
\hline $\mathrm{X} 7$ & .014 & .074 & .014 & .186 & .853 \\
\hline
\end{tabular}

Tabel 2

Koefisien Regresi

a. Dependent Variable: Y

Berdasarkan tabel 4.25 maka ringkasan hasil pengujian dapat diformulasikan persamaan regresinya sebagai berikut.

$Y=948+0,085 X+0,595 X 2-0,208 X 3-106 X 4+0,453 X 5+0,087 X 6+0,014$ X7

Dari persamaan regresi diatas, dapat diinterprestasikan sebagai berikut :

1. $a=948$ artinya tanpa variabel bebas ( variabel X) maka loyalitas nasabah tabungan sikoci bank nagari cabang simpang empat adalah 948 dengan asumsi variabel bebas yuitu kepercayaan, komitmen, bukti fisik (tangibles), keandalan (realibility), ketanggapan (responsiveness), jaminan (assurance), empati (empaty) tidak mengalami perubahan.

2. $\mathrm{b} 1=$ koefisien regresi 0.085 menunjukan bahwa setiap variabel kepercayaan bertambah 1 poin, maka peningkatan loyalitas nasabah tabungan sikoci akan bertambah sebesar 0.085 dengan asumsi variabel kepercayaan dianggap tetap.

3. $\mathrm{b} 2=$ koefisien regresi 0.595 menunjukan bahwa setiap variabel komitmen bertambah 1 poin, maka peningkatan loyalitas nasabah tabungan sikoci 
akan bertambah sebesar 0.595 dengan asumsi variabel komitmen dianggap tetap.

4. $b 3=$ koefisien regresi $-0,208$ menunjukan bahwa setiap variabel bukti fisik (tangibles) berkurang 1 poin, maka pengurangan loyalitas nasabah tabungan sikoci akan berkurang sebesar -0,208 dengan asumsi variabel bukti fisik (tangibles ) dari produk dianggap tidak tetap.

5. b4= koefisien regresi -0.106 menunjukan bahwa setiap variabel keandalan (reliability) berkurang 1 poin, maka pengurangan loyalitas nasabah tabungan sikoci akan berkurang sebesar -0,106 dengan asumsi variabel keandalan (reliability) dianggap tidak tetap.

6. $\mathrm{B} 5=$ koefisien regresi 0.453 menunjukan bahwa setiap variabel ketanggapan (responsiveness) bertambah 1 poin, maka peningkatan loyalitas nasabah tabungan sikoci akan bertambah sebesar 0.453 dengan asumsi variabel komitmen dianggap tetap.

7. $\mathrm{B} 6=$ koefisien regresi 0.087 menunjukan bahwa setiap variabel jaminan (assurance) bertambah 1 poin, maka peningkatan loyalitas nasabah tabungan sikoci akan bertambah sebesar 0.087 dengan asumsi variabel komitmen dianggap tetap.

8. $\mathrm{B} 7=$ koefisien regresi 0.014 menunjukan bahwa setiap variabel empati (empaty) bertambah 1 poin, maka peningkatan loyalitas nasabah tabungan sikoci akan bertambah sebesar 0.014 dengan asumsi variabel komitmen dianggap tetap.

\section{Uji simultan (uji F)}

\section{Tabel 3}

Hasil Uji F

\begin{tabular}{|l|l|l|l|l|}
\hline Variabel & F-hit & Sig & Alpha & Kesimpulan \\
\hline $\begin{array}{l}\text { kepercayaan, komitmen, bukti } \\
\text { fisik (tangibles), keandalan } \\
\text { (reliability), ketanggapan } \\
\text { (responsiveness), jaminan } \\
\text { (assurance), empati (empaty) }\end{array}$ & 19.447 & $.000^{\mathrm{a}}$ & & Signifikan \\
\hline
\end{tabular}

Sumber : data olahan 2018

Berdarsarkan hasil ringkasan hasil uji $\mathrm{F}$ yang di kemukakan pada tabel 4.26 diketahui variabel kepercayaan, komitmen, bukti fisik (tangibles), keandalan (reliability), ketanggapan (responsiveness), jaminan (assurance), empati (empaty) di temukan nilai sig atau probality sebesar 0,05 dalam melakukan penelitian, penulis melakukan tingkat kesalahan maksimal (level of signifikan) sebesar 5\% berarti nilai F-statistik untuk variabel lainnya $0,000<\alpha=0,5$ maka keputusan adalah Ha diterima dan Ho ditolak. Berarti dapat disimpulkan bahwa variabel kepercayaan, komitmen, bukti fisik (tangibles), keandalan (reliability), ketanggapan (responsiveness), jaminan (assurance), empati (empaty) memiliki pengaruh yang signifikan terhadap loyalitas nasabah tabungan sikoci secara serempak. 


\section{Uji persial (uji T)}

\section{Tabel 4}

Hasil Uji t

\begin{tabular}{|l|c|c|c|c|}
\hline \multicolumn{1}{|c|}{ Variabel } & t-hit & Sig & Alpha & Kesimpulan \\
\hline Kepercayaan & .944 & .348 & 0,05 & Tidak Signifikan \\
\hline Komitmen & 8.218 & .000 & 0,05 & Signifikan \\
\hline Bukti Fisik (Tangibles) & -2.430 & .017 & 0,05 & Signifikan \\
\hline Keandalan (Reliability) & -1.570 & .120 & 0,05 & Tidak Signifikan \\
\hline $\begin{array}{l}\text { Ketanggapan } \\
\text { (Responsiveness) }\end{array}$ & 5.922 & .000 & 0,05 & Signifikan \\
\hline Jaminan (Assurance) & 1.199 & .234 & 0,05 & Tidak Signifikan \\
\hline Empati (Empaty) & .186 & .853 & 0,05 & Tidak Signifikan \\
\hline
\end{tabular}

Sumber : data olahan 2018

Berdasarkan ringkasan hasil uji $\mathrm{t}$ seperti yang dikemukakan pada tabel 4.27 diketahui :

1. Berdasarkan hasil pengujian uji $T$ untuk variabel kepercayaan diatas dapat disimpulkan bahwa nilai $\mathrm{T}$ hitung kepercayaan terhadap loyalitas nasabah sebesar 0,944 dan $\mathrm{T}$ tabel 1,984 dengan signifikan 0,348>0,05. Hal ini berarti $\mathrm{T}$ hitung lebih kecil dari $\mathrm{T}$ tabel dan signifikan > 0,05 maka Ho ditolak dan Ha diterima, artinya variabel kepercayaan berpengaruh tidak signifikan terhadap loyalitas nasabah tabungan sikoci pada Bank Nagari cabang Simpang Empat.

2. Berdasarkan hasil pengujian uji $\mathrm{T}$ untuk variabel komitmen diatas dapat disimpulkan bahwa nilai $\mathrm{T}$ hitung komitmen terhadap loyalitas nasabah sebesar 8,218 dan $\mathrm{T}$ tabel 1,984 dengan signifikan $0,000<0,05$. Hal ini berarti $\mathrm{T}$ hitung lebih besar dari $\mathrm{T}$ tabel dan signifikan $<0,05$ maka Ho diterima dan Ha ditolak, artinya variabel komitmen berpengaruh signifikan terhadap loyalitas nasabah tabungan sikoci pada Bank Nagari cabang Simpang Empat.

3. Berdasarkan hasil pengujian uji $\mathrm{T}$ untuk variabel bukti fisik (tangibles) diatas dapat disimpulkan bahwa nilai $\mathrm{T}$ hitung reliability (keandalan) terhadap loyalitas nasabah sebesar $-2,430$ dan $\mathrm{T}$ tabel 1,984 dengan signifikan $0,017<0,05$. Hal ini berarti $\mathrm{T}$ hitung lebih besar dari $\mathrm{T}$ tabel dan signifikan < 0,05 maka Ho diterima dan Ha ditolak, artinya variabel reliability (keandalan) berpengaruh signifikan terhadap loyalitas nasabah tabungan sikoci pada Bank Nagari cabang Simpang Empat.

4. Berdasarkan hasil pengujian uji $\mathrm{T}$ untuk variabel keandalan (reliability) diatas dapat disimpulkan bahwa nilai $\mathrm{T}$ hitung keandalan (reliability) terhadap loyalitas nasabah sebesar -1.570 dan $\mathrm{T}$ tabel 1,984 dengan signifikan $0,120>0,05$. Hal ini berarti $\mathrm{T}$ hitung lebih kecil dari $\mathrm{T}$ tabel dan signifikan > 0,05 maka Ho ditolak dan Ha diterima, artinya variabel keandalan (reliability) berpengaruh tidak signifikan terhadap loyalitas nasabah tabungan sikoci pada Bank Nagari cabang Simpang Empat.

5. Berdasarkan hasil pengujian uji $\mathrm{T}$ untuk variabel ketanggapan ( responsiveness) diatas dapat disimpulkan bahwa nilai $\mathrm{T}$ hitung ketanggapan ( responsiveness) terhadap loyalitas nasabah sebesar 5.922 dan $\mathrm{T}$ tabel 1,984 dengan signifikan $0,000<0,05$. Hal ini berarti $\mathrm{T}$ hitung lebih besar dari $\mathrm{T}$ tabel dan signifikan $<0,05$ maka Ho diterima dan $\mathrm{Ha}$ 
ditolak, artinya variabel ketanggapan ( responsiveness) berpengaruh signifikan terhadap loyalitas nasabah tabungan sikoci pada Bank Nagari cabang Simpang Empat.

6. Berdasarkan hasil pengujian uji $\mathrm{T}$ untuk variabel jaminan (assurance) diatas dapat disimpulkan bahwa nilai $\mathrm{T}$ hitung jaminan (assurance) terhadap loyalitas nasabah sebesar 1.199 dan $\mathrm{T}$ tabel 1,984 dengan signifikan 0, $234>0,05$. Hal ini berarti $\mathrm{T}$ hitung lebih kecil dari $\mathrm{T}$ tabel dan signifikan > 0,05 maka Ho ditolak dan Ha diterima, artinya variabel jaminan (assurance) berpengaruh tidak signifikan terhadap loyalitas nasabah tabungan sikoci pada Bank Nagari cabang Simpang Empat.

7. Berdasarkan hasil pengujian uji $\mathrm{T}$ untuk variabel empati (empaty) diatas dapat disimpulkan bahwa nilai $\mathrm{T}$ hitung empati (empaty) terhadap loyalitas nasabah sebesar 0,186 dan T tabel 1,984 dengan signifikan 0,853 $>0,05$. Hal ini berarti $\mathrm{T}$ hitung lebih kecil dari $\mathrm{T}$ tabel dan signifikan > 0,05 maka Ho ditolak dan Ha diterima, artinya variabel empati (empaty) berpengaruh tidak signifikan terhadap loyalitas nasabah tabungan sikoci pada Bank Nagari cabang Simpang Empat.

\section{Uji determinasi $\left(\mathbf{R}^{2}\right)$}

\begin{tabular}{|c|c|c|c|c|c|}
\hline \multicolumn{6}{|c|}{$\begin{array}{l}\text { abel } 5 \\
\text { rminasi }\left(\mathbf{R}^{2}\right)\end{array}$} \\
\hline Model & $\mathrm{R}$ & R Square & $\begin{array}{l}\text { Adjusted R } \\
\text { Square }\end{array}$ & $\begin{array}{l}\text { Std. Error of } \\
\text { the Estimate }\end{array}$ & Durbin-Watson \\
\hline 1 & $.772^{\mathrm{a}}$ & .597 & .566 & 1.471 & 1.799 \\
\hline
\end{tabular}

a. Predictors: (Constant), X7, X3, X2, X4, X5, X6, X1

b.Dependent Variable: Y

Dari tabel maka ringkasan hasil kolerasi dan determinasi adalah sebagai berikut :

1. $\mathrm{R}=0.597$ berarti nilai kolerasi berada antara tidak berada antara 0,41 sampai dengan 0.71 berarti dari kepercayaan (X1), komitmen (X2), bukti ffisik (tangibles) (X3), keandalan (reliability) (X4), ketanggapan (responsiveness) (X5), jaminan (assurance) (X6), empati (empaty)(X7) terhadap loyalitas nasabah (Y) tidak memeiliki keeratan yang kuat.

2. Adjusted R Square $=566$ berarti 56.6\%. loyalitas nasabah tabungan sikoci dipengaruhi kepercayaan, komitmen, bukti fisik(tangibles), keandalan(reliability), ketanggapan (responsiveness), jaminan(assurance), empati (empaty) sedangkan sisanya $43,4 \%$ dipengaruhi oleh variabel lainnya selain model yang diteliti dalam penelitian ini seperti pengaruh citra perusahaan,penanganan keluhan dan lain sebagainya.

\section{SIMPULAN}

Berdasarkan hasil penelitian kepada pengguna tabungan sikoci di Bank Nagari cabang Simpang Empat yang berjumlah 100 orang nasabah, dikemukakan kesimpulan sebagai berikut : 
1. Kepercayaan berpengaruh positif dan tidak signifikan terhadap loyalitas nasabah tabungan sikoci hal ini dilihat dari nilai thitung $(944)<\mathrm{t}$ tabel $(1,984)$.

2. Komitmen berpengaruh positif dan signifikan terhadap loyalitas nasabah tabungan sikoci hal ini dilihat dari nilai thitung $(8.218)>\mathrm{t}$ tabel $(1,984)$.

3. Bukti fisik (Tangibles) berpengaruh negatif dan signifikan terhap loyalitas nasabah tabungan sikoci ini dilihat dari nilai thitung $(-2.430)>t$ tabel $(1,984)$.

4. Keandalan (Reliability) berpengaruh negatif dan tidak signifikan terhadap loyalitas nasabah tabungan sikoci hal ini dilihat dari nilai thitung $(-1.570)$ $<\mathrm{t}$ tabel $(1,984)$.

5. Ketanggapan (responsiveness) berpengaruh positif dan signifikan terhap loyalitas nasabah tabungan sikoci ini dilihat dari nilai thitung $(5.922)>\mathrm{t}$ tabel $(1,984)$.

6. Jaminan (assurance) berpengaruh positif dan tidak signifikan terhadap loyalitas nasabah tabungan sikoci hal ini dilihat dari nilai thitung (1.199) < t tabel $(1,984)$.

7. Empati (empaty) berpengaruh positif dan tidak signifikan terhadap loyalitas nasabah tabungan sikoci hal ini dilihat dari nilai thitung $(186)<\mathrm{t}$ tabel $(1,984)$.

\section{UCAPAN TERIMA KASIH}

Dalam penysunan skripsi ini penulis banyak mendapatkan bantuan dan dukungan moril maupun materil dari berbagai pihak. Untuk itu penulis mengucapkan terima kasih kepada :

1. Bapak Febryandhie Ananda,S.E,M.Si. selaku Ketua STIE"KBP'Padang.

2. Ibu Lidya Martha, SE., MM selaku Wakil Ketua STIE “KBP”Padang

3. Ibu Febsri Susanti,SEI.MM selaku Ketua Program Studi Manajemen STIE'KBP'Padang.

4. Bapak Alfian SE.MM. sebagai Pembimbing yang dengan penuh perhatian memberi bimbingan pemikiran dan dorongan semangat serta masukan dan arahan dalam pembuatan skripsi ini.

5. Ibu Maria Magdalena,Spd,MM selaku Penasehat Akademik Program Studi Manajemen.

6. Terima kasih yang sedalam-dalamnya untuk semua dosen yang telah mengajar dan memberikan ilmunya kepada saya sehingga saya bisa menyelesaikan studi ini. Terima kasih yang sedalam - dalamnya untuk seluruh seluruh karyawan dan karyawati AKBP STIE "KBP” Padang.

7. Keluarga yang sangat saya cintai ibu, ayah, kakak, abang, dan keponakankeponakan yang selalu mendo'akan, menjadi penyemangat dan mendukung penuh saya baik secara moral, materil maupun spiritual sehingga anak dan adik tercintanya mampu menyelesaikan pendidikan jenjang Strata 1 di STIE "KBP" Padang. Semoga saya bisa menjadi kebanggaan bagi keluarga, amin. 


\section{DAFTAR PUSTAKA}

Anggraini, L., \& Alfian, A. (2018). Pengaruh Customer Relationship Management Dan Kualitas Pelayanan Terhadap Loyalitas Nasabah Kredit Komersil Pada Bank Nagari Sumatera Barat Cabang Painan. Https://Doi.Org/10.31219/Osf.Io/Jmavq

Atika Sefesiyani, A. F. D. \& Z. A. (2015). Pengaruh Relationship Marketing ( Pemasaran Relasional ) Terhadap Kepuasan Nasabah Serta Dampaknya Pada Loyalitas Nasabah ( Survei pada Nasabah Tabungan Bank Central Asia Kantor Cabang Pembantu Dinoyo Kota Malang ). Jurnal Administrasi Bisnis (JAB), 28(2), 1-8.

Ayu, G., Ratih, P., Dewi, K., Nyoman, N., Yasa, K., \& Sukaatmadja, P. G. (2014). Pengaruh kualitas pelayanan terhadap kepuasan dan loyalitas nasabah pt bpr hoki di kabupaten tabanan, 5, 257-275.

Cahyani, N. (2015). Pengaruh Citra Perusahaan, Relationship Marketing Dan Kualitas Pelayanan Terhadap Loyalitas Pelanggan Melalui Kepuasan Pelanggan (Studi Pada Bank Rakyat Indonesia (BRI) Kantor Cabang Wonosari). SKRIPSI Fakultas Ekonomi Universitas Negeri Yogyakarta.

Chan, Syafruddin. (2003). Relationship Marketing:Inovasi Pemasaran yang Membuat Pelanggan Bertekuk Lutut.Jakarta: Gramedia Pustaka Utama.

Dona, E. (2018). Kepuasan Publik Dilihat Dari Kualitas Pelayanan Dalam Pengurusan Perizinan (Kasus Badan Pelayanan Perizinan Terpadu, Pengadaan Barang Dan Jasa Kab. Dharmasraya). Https://Doi.Org/10.31227/Osf.Io/8cjhg

Fernandes, Y. D., \& Marlius, D. (2018). Peranan Customer Service Dalam Meningkatkan Pelayanan Kepada Nasabah Pada PT. Bank Pembangunan Daerah Sumatera Barat Cabang Utama Padang. https://doi.org/10.31227/osf.io/wrh3p

Fernos, J., \& Putra, Y. E. (2019). Analisa Pengaruh Kualitas Pelayanan Terhadap Kepuasan Nasabah Pada PT. Bank Mega Syari'ah Padang. https://doi.org/10.31219/osf.io/y2baf

Marlius, D. (2017). Keputusan Pembelian Berdasarkan Faktor Psikologis Dan Bauran Pemasaran Pada PT. Intercom Mobilindo Padang. Jurnal Pundi. Volume 1. No. 1. Hal. 57-66. https://doi.org/10.31575/jp.v1i1.9

Marlius, D. (2016). Pengaruh Bauran Pemasaran Jasa Terhadap Minat Nasabah Dalam Menabung Pada Bank Nagari Cabang Muaralabuh. https://doi.org/10.31227/osf.io/vdqgx

Marlius, D. Putriani, I. (2019). Kepuasan Nasabah PT. Bank Rakyat Indonesia Unit Tapan Cabang Painan Dilihat dari Kualitas Layanan Customer Service. Jurnal Pundi. Volume 3. No. 2. Hal.111-122. https://doi.org/10.31575/jp.v3i2.151

Marlius, D. Ananda, F. (2019). Pengaruh Kualitas Pelayanan Website Akademik Terhadap Minat Kuliah di AKBP Padang. Jurnal Pundi, Vol. 03, No. 03. Hal. 191-204. https://doi.org/10.31575/jp.v3i3.190

Marlius, D. (2018). Loyalitas Nasabah Bank Nagari Syariah Cabang Bukittinggi Dilihat Dari Kualitas Pelayanan. Jurnal Pundi. Volume 1. No. 3. Hal.12-22. https://doi.org/10.31575/jp.v1i3.60 
Marlius, D. (2018). Pengaruh Dimensi Kualitas Pelayanan Website Akademik Terhadap Kepuasan Mahasiswa Pada STIE “KBP”. Jurnal Ipteks Terapan. Volume 12. No. 2. Hal. 116-128. http://doi.org/10.22216/jit.2018.v12i2.633

Marlius, D. RD Putra. (2018). Strategi Pengembangan Sulam Bayang. Jurnal Benefita: Ekonomi Pembangunan Manajemen Bisnis Dan Akuntansi. Volume 3. No. 2. Hal. 204-218. http://doi.org/10.22216/jbe.v3i2.3494

Mayliza, R. (2019). Analisis Customer Satisfaction Dan Behavioral Intention Dilihat Dari Service Quality, Food Quality Dan Price/Value Di Restoran Mc Donald's Depok. https://doi.org/10.31219/osf.io/e2jrt

Putra, Y. E., \& Aziz, N. (2019). Pengaruh Kualitas Pelayanan Dan Kepuasan Pelanggan Terhadap Loyalitas Nasabah PT. Bank Rakyat Indonesia Cabang Padang. https://doi.org/10.31219/osf.io/hcsw2

Santoso, S., \& Oetomo, H. W. (2013). Pengaruh Kualitas Pelayanan Terhadap Loyalitas Pelanggan, 2(6).

Saputra, M.H. (2008). Pengaruh Relationship Marketing Pada Loyalitas Mahasiswa Program Magister Sains Fakultas Ekonomika Dan Bisnis Universitas Gadjah Mada. Yogyakarta.

Sungkono, S. H. B. (2014). Pengaruh Relationship Marketing Dan Kualitas Layanan Terhadap Loyalitas Pelanggan. Jurnal Ilmu \& Riset Manajemen, 3(10), 1-16.

Sugiyono. (2015). Statistik Nonparametris Untuk Penelitian. Book. Bandung: CV. Alvabeta.

Susanti, F. W Ekazaputri. (2018). Service Performance Dan Kepuasan Sebagai Moderating Variabel Terhadap Loyalitas Nasabah Pada PT BPR Labuh Gunung Payakumbuh Jurnal Benefita: Ekonomi Pembangunan Manajemen Bisnis Dan Akuntansi. Volume 3. No. 3. Hal. 433444.http://doi.org/10.22216/jbe.v3i3.3472

Syaiful, M. (2015). Pengaruh Relationship Marketing, Komitmen Dan Kepercayaan Terhadap Loyalitas Pelanggan AUTO 2000 SUNGKONO. Jurnal Ilmu Dan Riset Manajemen Volume 4, Nomor 12, Desember 2015, 4.

Syauqillah, M. (2016). Analisis pengaruh relationship marketing terhadap kepuasan dan loyalitas pelanggan pt trans express 2 tour \& travel malang. Skripsi Fakultas Ekonomi Universitas Islam Negeri Maulana Malik Ibrahim Malang.

Widyastuti, Y. \& A. W. (2014). Analisis pengaruh relationship marketing terhadap loyalitas pelanggan. Jurnal Ilmu \& Riset Manajemen, 3(6), 1-21.

Widodo, B. H., \& Susanti, F. (2019). Pengaruh Human Relation (Hubungan Antar Manusia), Lingkungan kerja Terhadap Etos Kerja karyawan (Studi Kasus Pada PT. Pelindo Teluk Bayur Padang). https://doi.org/10.31227/osf.io/dxm8a 